\title{
The Role of School Governing Bodies in Underperforming Schools of Western Cape: A Field Based Study
}

\author{
Amiena Bayat
}

Department of Economics; Faculty of Economic and Management Sciences, University of the Western Cape, Private Bag: X 17; Robert Sobukwe Road, Bellville, South Africa

Email: amienabayat@telkomsa.net

Wynand Louw

Institute for Social Development; University of the Western Cape, Private Bag: X 17; Robert Sobukwe Road, Bellville, South Africa

Email: jwl@netactive.co.za

\section{Prof Ravinder Rena}

Department of Economics; Faculty of Economic and Management Sciences, University of the Western Cape, Private Bag: X 17; Robert Sobukwe Road, Bellville, South Africa 7535 Email: rrena@uwc.ac.za; drravinderrena@gmail.com

\section{Doi:10.5901/mjss.2014.v5n27p353}

\section{Abstract}

The schools in South Africa have been facing immense challenges for a long period of time especially after independence in 1994. The School Governing Bodies (SGBs) play a major role in the administration and finance functions of the school and its development however, school governing bodies are sometimes used by individuals and organised groups to discriminate against learners in South Africa. It is found that some SGBs are not working properly because they do not have the necessary skills and they are not sure about their roles and responsibilities. This indeed happens in poorer communities, where people have few resources and many cannot read and write. The situation is made worse by the fact that some of the schools do not get enough money, support and training from the government. A strong sentiment amongst teachers was that the core of the problem of ineffectual SGBs was located in bad leadership and management. In light of the above challenges an attempt is made in this article to discuss the definition of the role of the School Governing Bodies (SGBs) in terms of the South African Schools Act. The article also focuses on the findings that were generated through responses to a number of questions around the theme of school governing bodies that were included in the questionnaires administered to principals and teachers. Principals are, in terms of the School Act of 1996, ex officio members of the SGB.

Keywords: School Governing Bodies, School Management Team (SMT), Principal, Underperformance of learners, Curriculum development, Financial Management

\section{Introduction}

The quality education is considered to be a corner stone of economic development and social transformation. Educational quality and its development are therefore regarded as indispensable for the teaching and learning process (Rena 2008). It has become an established fact that South Africa's schools fare poorly in international comparison, even among African countries. Among 12 African countries participating in the Major Lindsey and Africa (MLA) study in 1999, South African Grade 4 learners scored lowest in numeracy and fourth lowest in literacy. The vast majority of children attending disadvantaged schools do not acquire a basic level of mastery in reading, writing and mathematics. In its global rankings, the World Economic Forum (2013) recently ranked South Africa second last in the world for math and science education, just ahead of Yemen (Bayat, Louw and Rena, 2014:183).

The government of South Africa has acknowledged that "the quality of school education for black people is poor" across the country. Van der Berg (2008: 2; cf. Bloch 2009) found that "educational quality in historically black schools which constitute $80 \%$ of enrolment and are thus central to educational progress - has not improved significantly since political transition." Educators, principals, school management teams and school governing bodies in South Africa 
repeatedly stressed the view that primary schools are continuously failing to lay a solid educational foundation, especially with regard to numeracy and literacy. Education experts often say that the government of South Africa has to overcome years of underinvestment in black education under Apartheid. With the aim of promoting learner achievement, the Government of South Africa embarked on many educational reform changes. These reforms have met with limited success.

Prior to the South Africa's first democratic government in 1994, school improvement in the country was dominated by NGO projects, generally small in scale and focusing largely on teacher development. Since 1994, the field of school improvement and effectiveness has become pluralized, with government entering the fray, and the introduction of a variety of programmes, including systemic and standards-based approaches (Taylor 2007).

As part of its drive to undo the legacy of years of race-based, inequitable development in South Africa, the first democratically elected government embarked on an ambitious programme of socio-economic reconstruction and redress in its quest to establish a more fair society. The school system was one of the first sectors to be addressed and since 1995; it has undergone fundamental change to improve the provision of schooling for those that were previously discriminated against. This included substantial reallocation of an ever-increasing portion of the annual budget to improve existing and establish new resources and services.

Although near universal access to primary school has been achieved, the quality of education in both primary and secondary schools has been disappointing. Results from international benchmark tests show our learners are consistently out-performed by learners from poorer countries. In the Western Cape Province of South Africa, the location of our research, the number of underperforming secondary schools (i.e. those with a matric pass rate of less than 60\%) has more than doubled since 2006 and 2009. The aim of this study was to better understand what aspects of the governance of schools were responsible for these institutions performing badly.

In 1995 the post-Apartheid government's new national Ministry of Education started to develop structures to give expression to the principals of decentralisation, inclusivity and participation. Under Apartheid schools were treated as hostile institutions that belonged to the oppressive political dispensation. The new government had to strategise to bring previously disenfranchised communities and schools closer together. This was achieved by developing new entities, anchored in the community, thereby encouraging their involvement in the co-control and management of educational institutions. According to Gamage, (1994, quoted in van Wyk, 2004) this devolution of authority was intended to result in stronger and closer relationships between schools and communities. Such spreading of power to the stakeholder community would (in theory) then ultimately provide an alternative form of accountability to bureaucratic surveillance. The result of this process was the establishment of School Governing Bodies (SGBs).

\subsection{The Role of School Governing Bodies (SGBs)}

In the past, school governance in South Africa was characterized by a top-down approach. Educators, learners, parents and communities were excluded from making important decisions about schools. Principals and inspectors were the main decision makers for the schools. The racially based system of education gave white parents decision-making powers. This was not the case in schools serving black communities. Many communities, though, formed Parent, Teacher, Student Associations (PTSAs). As part of efforts to make schools democratic, the South African Schools Act (SASA) was passed in 1996. An important provision in the Act was the establishment of democratically elected school governing bodies (SGBs). The schools in South Africa have been facing immense challenges for the two decades of its independence. Bringing decision making closer to the people is desirable but this by itself will not solve all the problems and challenges faced by school governing bodies in South Africa. Research has revealed that school governing bodies face many problems despite the fact that decisions are made by people who are closest to the situation. School governing bodies are sometimes used by individuals and organised groups to discriminate against learners. Some SGBS are not working properly because they do not have the necessary skills and they are not sure about their roles and responsibilities. This mostly happens in poorer communities, where people have few resources and many cannot read and write. The situation is made worse by the fact that some of the schools do not get enough money, support and training from the government.

In 2003, the Minister of Education appointed a task team to investigate how school governing bodies are working and to make recommendations about how they can work better. This shows that the government realises and accepts that school governing bodies face serious problems in their day-to-day working (Ramadiro and Salim, 2005: 2).

School governance is about creating, implementing, supervising and evaluating policies and rules, which guide and govern the actions of the school and its members. In other words, school governance is concerned with the creation of policies for the school and making sure that the school is run according to the set policies (Ramadiro and Salim, 2005: 2- 
3). School governance is also about raising money for the school. Parents or caregivers must form a majority of members of a school governing body because according to the South African Schools Act they are the ones who have the primary responsibility for ensuring that the school is run well. What is the difference between school governance and school management? School management is about the day to day running of the school (Ramadiro and Salim, 2005: 2-3; Raj,2006). In other words, school management is about the organisation of the teaching and learning in a school and related activities (e.g. managing staff, detailed planning of the curriculum, assessing learners and educators). The principal together with the School Management Team (SMT) is responsible for school management. An attempt is made in this article to explore the role of SGBs in the management and development of school system in Western Cape Province of South Africa. The paper provides some policy implications on how best the SGBs and SMTs can play a pivotal role in improving the underperforming schools.

\subsection{Research Questions and Objectives}

Although the basic legislation aims to ensure that schools manage their funds effectively it is evident that this is not always the case. Against this background, the research problem was encapsulated by means of the following questions:

What are the perceptions of parents and educators with regard to the role of school governing body?

What are the functions of the school governing body in education and school development?

What guidelines may be developed to enable principals and SGBs to manage their schools' administration and finances efficiently?

The main objective of the research was to explore the perceptions of stakeholders with regard to the general functions of the school governing bodies. In order to attain the general aim of the study, the specific aims were:

- To determine the functions of the school governing body;

- To develop guidelines aimed at assisting the SGB in conjunction with the principal to acquire the skills for managing their school's administration and finances efficiently.

Based on the above research questions and objectives the following methodology was adopted to solve the research problem.

\section{Methodology and Data Source}

This research methodology consisted of both quantitative and qualitative approaches (included a combination of field work, interviews, literature and document reviews and desktop analysis). The unit of analysis was done in underperforming secondary schools in the Western Cape Province. The sampling frame consisted of underperforming secondary schools based on the 2009 final national Grade 12 examinations and consisted of 22 (out of 78) secondary schools for which detailed data was available at the time of finalising the sampling frame and sample population. All questionnaires were checked for correct completion by the research team before learners left the group. Data was then captured in Statistical Package for the Social Sciences (SPSS) then data analysis commenced. The fieldwork was conducted during February and March 2011. All questionnaires were piloted and amended during the first school visit but given the fact that negotiating access to schools was difficult, and only minor adjustments were necessary after the pilot, it was decided to include these interviews as part of the final dataset.

Three survey instruments (questionnaires) were developed: one for completion by the principals; one for educators; and one for learners. Questionnaires were developed to measure a range of aspects shown by literature to impact on the functionality of SGBs in school and thus the academic performance of its learners.

Inferential statistics were used to draw inferences about a population from a sample. Indeed the goal of statistical analysis is to answer 2 questions: 1 ) Is there a significant effect/association/difference between the variables of interest i.e. school governing bodies (SGB), School Management Team (SMT) and the performance of high school learners? 2) The research also examined how big the effect/association/difference was? The study used mean, median, mode and standard deviation techniques.

The sampling frame consisted of all 14 underperforming schools which were purposefully selected to ensure representation for both ethnic and location (urban/rural) variables. For the purpose of this study, rural schools were defined as all schools outside the Cape Metropolitan Area (Metro).

The 14 schools which constituted the sample comprised nine urban and five rural schools. Of the nine urban schools, four were classified as historically Coloured schools and five as historically African schools. In the case of the five rural schools, three were historically African and two historically Coloured schools. Unfortunately, access to some 
schools was exceedingly difficult as principals of historically African schools were unwilling to partake in the study after being informed of its purpose. After exhausting the replacement list, it became necessary to include additional schools not part of the original sampling frame to complete the fieldwork. Due to time frame constraints, the team still had to settle with the completion of only 12 schools, instead of the intended 14.

The fieldwork was conducted over a period of eight weeks i.e. during February and March 2011. All questionnaires were piloted and amended during the first school visit but given the fact that negotiating access to schools was difficult, and only minor adjustments were necessary after the pilot, it was decided to include these interviews as part of the final dataset.

Three survey instruments (questionnaires) were developed: one for completion by the principals; one for educators; and one for learners. Questionnaires were developed to measure a range of aspects shown by literature to impact on the functionality of a school and thus the academic performance of its learners. Table 1 below provides a broader account of the type of questions included in the questionnaires by indicating categories of questions for each respondent group.

Table 1: Questionnaire categories as for each respondent group

\begin{tabular}{|l|c|c|c|}
\hline Questionnaire category & Respondent group & & \\
\hline & Principal & Teachers & Learners \\
\hline School profile & $\checkmark$ & & \\
\hline Individual profile & $\checkmark$ & $\checkmark$ & $\checkmark$ \\
\hline Human resource management & $\checkmark$ & $\checkmark$ & $\checkmark$ \\
\hline Staff related aspects & $\checkmark$ & $\checkmark$ & \\
\hline Learner related aspects & $\checkmark$ & $\checkmark$ & \\
\hline School facilities & $\checkmark$ & $\checkmark$ & $\checkmark$ \\
\hline Curriculum management & $\checkmark$ & $\checkmark$ & $\checkmark$ \\
\hline Curriculum implementation & & $\checkmark$ & \\
\hline Parental and other community involvement & $\checkmark$ & $\checkmark$ & $\checkmark$ \\
\hline School governance and management & $\checkmark$ & $\checkmark$ & \\
\hline General questions (e.g. testing future perspective) & & & $\checkmark$ \\
\hline
\end{tabular}

Educators were randomly selected from staff lists provided by the school, with two educators selected for each grade offered by the school. Learners were randomly selected from class lists provided by the school with eight learners selected from each grade. The total numbers of questionnaires completed were: 11 principal questionnaires, 84 teacher questionnaires and 436 learner questionnaires. Semi-structured interviews were conducted with the School Management Team (SMT) of each school and focus group discussions were held with available members of the School Governing Bodies (SGBs) of the selected schools. These interviews were then transcribed and analysed.

\section{Results and Discussion}

This article focuses on the findings that were generated through responses to a number of questions around the theme of school governing bodies that were included in the questionnaires administered to principals and teachers. Principals are, in terms of the School Act of 1996, ex officio members of the SGB. They perform a critical function on the SGB, articulating the needs and challenges of their respective schools as well as share the achievements of the learners and teachers of their schools with the members of the SGB. They should bring continuity in the relationship between the school and the SGB. Principals, in addition, should be the conduit whereby decisions taken and sentiments expressed by SGBs are fed back to the school community, i.e. the SMT, teachers, learners and administrative staff of the school. Principals are thus expected to play an active role and have a keen interest in the well being of SGBs.

\subsection{Legal Status of SGBS}

In getting a sense of their perspective on the level of functioning and effectiveness of the SGB, questions were asked to both principals and teachers. SGBs were described as functional with $82 \%$ of principals indicating this to be the case. An unexpected finding was that two principals indicated that the SGB at their school was not legally constituted. Another principal could not state with any certainty whether this was the case at his school. As mentioned above, the Schools Act 
is very clear on the responsibility of schools in South Africa to have a legally constituted and functioning SGB.

\subsection{Value of SGB to school functioning}

When questioned about the extent to which the governing body contributed to the functioning of underperforming schools, (61.9\%) of teachers agreed that SGBs do add value to the school. In the case of the principals, respondents were much more split in their opinion, with nearly half (36.9\%) taking a dim view of their contribution to effective functioning of the school (see table 2 . Nearly $18.2 \%$ of principals were very positive about their SGBs contribution, while slightly more than a third described the contribution as moderate (see table 3). The findings are reflected in the tables below:

Table 2: Extent to which SGB contributes to effective functioning of school (teachers)

\begin{tabular}{|c|c|c|c|}
\hline & Frequency & Percent & Cumulative Percent \\
\hline Don't know & 1 & 1.2 & 1.2 \\
\hline Yes & 52 & 61.9 & 63.1 \\
\hline No & 31 & 36.9 & 100.0 \\
\hline Total & 84 & 100.0 & \\
\hline
\end{tabular}

Source: Primary data

Table 3: Extent to which SGB contributes to effective functioning of school (principals)

\begin{tabular}{|c|c|c|c|}
\hline & Frequency & Percent & Cumulative Percent \\
\hline Large extent & 2 & 18.2 & 18.2 \\
\hline Moderate extent & 4 & 36.4 & 54.5 \\
\hline Small extent & 5 & 45.5 & 100.0 \\
\hline Total & 11 & 100.0 & \\
\hline
\end{tabular}

Source: Primary data

The finding suggests that SGBs attached to underperforming schools are not meeting the expectations of school principals in any meaningful way. This is disappointing as it can be argued that the more in need for (additional and external) assistance and support a school is, the more strategically important the facilitative and empowerment role of SGBs become. Principals, by virtue of their position in the school and on the SGB, have infinitely more contact with SGBS and are thus in a better position to assess the SGB's contribution and value than teachers.

\subsubsection{Relationship between SGB, principal and teachers}

During this study, most teachers expressed their dissatisfaction with SGB structures at their respective school primarily lies with poor management within the SGB, as well as due to the fact their members seemingly do not understand their function and do not take their duties seriously. Other aspects mentioned was a lack of feedback to teachers from SGBs on schools matters that concern them directly.

Further, teachers were deeply unhappy with what they perceived as poor support from SGBs specifically regarding issues related to teaching in the classroom. In this regard specific reference was made to disciplinary issues reported to the SGB. Another aspect was the conflict that existed between the different stakeholders, i.e. SGBs, principals and/or teachers. It was mentioned that this conflict often results in the formation of different camps, leaving parties paralyzed and unable to perform their core functions.

\subsection{Relationship between SGB and other Stakeholders}

The majority of principals $(73 \% ; \mathrm{N}=8)$ indicated that they usually involve the $\mathrm{SGB}$ in decision-making pertaining to management aspects of the school. 
Table 4: Extent of involvement of principals in SGB decision making

\begin{tabular}{|c|c|c|c|}
\hline & Frequency & Percent & Cumulative Percent \\
\hline Sometimes & 3 & 27.3 & 27.3 \\
\hline Most of the time & 5 & 45.5 & 72.7 \\
\hline Always & 3 & 27.3 & 100.0 \\
\hline Total & 11 & 100.0 & \\
\hline
\end{tabular}

Source: Primary data

The quality of relationship, as perceived by the principals, between the teaching staff and the SGBs was also explored. Although teachers have representation on these boards, the relationship between these two parties is sometimes tense and characterised by mistrust and conflict (Brown and Duku, 2008). This was also evident from this research.

Table 5: Good working relationship between SGB and teachers (assessment of principals)

\begin{tabular}{|c|c|c|c|}
\hline & Frequency & Percent & Cumulative Percent \\
\hline No answer & 1 & 9.1 & 9.1 \\
\hline Yes, always & 2 & 18.2 & 27.3 \\
\hline Yes, sometimes & 6 & 54.5 & 81.8 \\
\hline No, never & 2 & 18.2 & 100.0 \\
\hline Total & 11 & 100 & \\
\hline
\end{tabular}

Source: Primary data

As table 5 explains, slightly less than $18.2 \%$ of principals described the relationship between school governing bodies and teachers to always be good, while about $55 \%$ was of the opinion that this relationship is sometimes good. Nearly $18.2 \%$ thought the relationship to be broken and thus dysfunctional. These results are to be expected especially in the case of schools where the parent community and teacher corps often have different educational levels and represent vastly different social and economic classes. This finding is consistent with another one established in this study, i.e. that a large percentage of governors are highly critical of the general behaviour and commitment of the teacher corps at underperforming schools in the Western Cape.

\subsection{Support}

In a related question principals had to indicate to what measure SGBs support them in the execution of their tasks and duties. In this instance their responses were more positive as is illustrated below:

Table 6: Extent to which SGB supports principal in the execution of tasks

\begin{tabular}{|c|c|c|c|}
\hline & Frequency & Percent & Cumulative Percent \\
\hline Large extent & 4 & 36.4 & 36.4 \\
\hline Moderate extent & 4 & 36.4 & 72.7 \\
\hline Small extent & 3 & 27.3 & 100.0 \\
\hline Total & 11 & 100.0 & \\
\hline
\end{tabular}

Source: Primary data

Table 6 explains that thirty six percent indicated that they were very satisfied, with the same percentage giving a qualified positive response. A relatively high percentage, i.e. $27 \%$, of principals was clearly not happy with the support received from their schools' SGB.

In the following question principals were asked to state in what areas they expected SGBs to support them in. The following four areas were mentioned in this regard: 
- Financial management including the drawing up and management of the budget

- Appointment of teachers

- Assisting in disciplinary actions with regard to both school staff and learners

- Managing the school infrastructure (that is physical buildings)

The results showed that there was a serious disjuncture between what was expected from SGBs and what was actually realised. This was clear from the two thirds of principals who said they received poor support from the SGB when drawing up the annual budget for their respective schools. In this regard it is interesting to note that $91 \%$ of principals mentioned that they would welcome additional support in the specific area of budgeting. This is indicative of the lack of support received from SGBs tasked with this function.

A crucial function of SGBs is to assist their school in developing policies, some dealing with sensitive and controversial issues like school admission criteria, recommendations regarding the appointment of teachers, the Language of Learning and Teaching ( LOLT) of the school as well as the disciplinary code or regime to be applied to learners and teachers. The research probed principals on two issues; firstly if the SGB is capable of participating in the process of policy formulation and secondly whether they participate in this process in any meaningful way.

Table 7: SGB capable of assisting in policy formulation

\begin{tabular}{|c|c|c|c|}
\hline & Frequency & Percent & Cumulative Percent \\
\hline No answer & 1 & 9.1 & 9.1 \\
\hline Yes, always & 1 & 9.1 & 18.2 \\
\hline Yes, sometimes & 7 & 63.6 & 81.8 \\
\hline No, never & 2 & 18.2 & 100.0 \\
\hline Total & 11 & 100.0 & \\
\hline
\end{tabular}

Source: Primary data

Table 7 presents that only one principal (9\%) thought SGBs were capable of generally contributing to policy formulation, $63.6 \%$ thought it is only possible at times, while $18.2 \%$ indicated the SGB was not at all capable of doing this.

Table 8: SGB involved in policy formulation

\begin{tabular}{|c|c|c|c|}
\hline & Frequency & Percent & Cumulative Percent \\
\hline Yes, always & 4 & 36.4 & 36.4 \\
\hline Yes, sometimes & 6 & 54.5 & 90.9 \\
\hline No, never & 1 & 9.1 & 100.0 \\
\hline Total & 11 & 100.0 & \\
\hline
\end{tabular}

Source: Primary data

Slightly more than a third of principals indicated that SGBs were always involved when issues of policies were dealt with whilst the other 55\% stated that this involvement happens at times. Only in the case of one school did the SGB never involve itself in policy issues.

One principal reacted in a cynical fashion to this question: "I can list an impressive number of things they are involved with, but actually they do nothing, they have no capacity to do anything worthwhile".

An interesting anomaly that became evident from the findings is that, although less than $50 \%$ of principals thought SGBs added any real value in terms of what could be described as advanced capacity (i.e. technical or financial contributions to their respective schools), more principals were positive about the general support they received from SGB $(72 \% ; N=8)$.

The findings suggest that there is a capacity problem in a number of SGBs. It is significant that responses were slightly more negative in relation to questions around the ability of SGBs, than to those relating to their actual involvement. This could be interpreted as a veiled motion of no confidence in their ability. Also, if this assessment is accurate, it points to an unhealthy situation where governors are involved in formulating crucial policy formulation without the inert ability to participate in this process. This can, and probably does, result in inappropriate and/or ineffectual 
policies that impact negatively on the functioning and performance of schools.

The negative perspective of a significant number of principals regarding the ability of their governors to engage on a policy level raises the issue of the training of SGB members and the results of this study point to a need for this. Principals were asked to indicate whether members of their SGB had received training.

The majority of principals (82\%; $N=9$ ) indicated that their SGB members had been for training since the body was constituted (see table 9). It would thus seem that the effectiveness of, as well as the format and content of this training might need to be reviewed.

Table 9: SGB members received training since it was constituted

\begin{tabular}{|c|c|c|c|}
\hline & Frequency & Percent & Cumulative Percent \\
\hline Yes & 9 & 81.8 & 81.8 \\
\hline No & 2 & 18.2 & 100.0 \\
\hline Total & 11 & 100.0 & \\
\hline
\end{tabular}

Source: Primary data

\subsection{Chronic conflict and tense relationships between SGBs and school staff}

Tense relations exist between the SGBs and staff members. This often rendered the body ineffectual, as it was unable to reach consensus and could therefore, not take firm action or make crucial decisions on issues of strategic importance to the school. Examples of these internal conflicts are issues over discipline regarding disruptive and/or dangerous learners, the appointment of teachers and issues relating to the school budget and general finances. Another area of tension is the relationship between the SGB and the principal. This is in stark contrast to SGB members describing the relationship between the principal and themselves as being mostly good or excellent. Besides, the conflict between the SGBs and teachers was also mentioned as a serious obstacle. Teachers at two schools alleged that the staff was at loggerheads with the SGB over a range of issues for virtually the entire year resulting in a complete breakdown of communication and working relationship between the school and the SGB.

However, a more general sentiment expressed by teachers was that SGB members do not show the required support and that they are not seen to be open and approachable. They also referred to them being disinterested in the teacher corps, showing a lack of compassion for the position of teachers at underperforming schools and are not interested in discussing problems facing teachers in the classroom.

Teachers were particularly critical about the negative view that SGB members tended to have of educators teaching at underperforming schools. It was alleged that the only meaningful contact with governors was when they are disciplined, threatened or criticised by them.

\subsection{Ineffectual SGBS}

A disturbing sentiment was that SGBs at underperforming schools add no value. One teacher stated: "although they are present they are not visible". Another respondent described the SGB as "worth nothing, the SGB is absent - they are there, in theory, but do nothing, they do not contribute to this school". A number of teachers pointed out that regular meetings did take place, but that this did not cause anything to change at the school and teachers were therefore of the view that SGBs had no impact. At one of the biggest townships schools visited on the Cape Flats, teachers alleged that governors shine in their persistent absence. One teacher said: "I can't even identify one member of the SGB".

\subsection{Management issues}

A strong sentiment amongst teachers was that the core of the problem of ineffectual SGBs was located in bad leadership and management. SGB chairmen and their management were described as "weak, erratic or autocratic". SGBs were accused of either making no real decisions, or not implementing them, and often not carefully considering the implications of those they did manage to implement. Often important information was not fed back to the teachers or SMTs. Teachers alleged their active participation on the SGB was not encouraged by the governors, with chairmen often threatened by their presence. 
A further allegation made by a number of teachers was that some lacked the urgency to become involved in the affairs and challenges of the schools. They attributed this to the domineering role that some principals are allowed to play. It was alleged that, in some instances, they virtually control the SGB which they blamed on weak or near-absent leadership in the SGB. According to some teachers, SGBs tend to create chasms between them and the school they suppose to support, serve and govern.

\title{
3.8 Lack of capacity in SGBS
}

According to many teachers a core shortcoming of SGBs relates to the general lack of capacity amongst the governors, including some chairmen. This, in their view, was mainly due to a lack of formal education. The situation prevents SGBS to fully understand and come to grips with some of the policies of the Western Cape Education Department (WCED), what they intend to achieve and how they should be implemented and monitored. It was pointed out that this fundamental shortcoming renders SGBs ineffectual with serious consequences for the schools served by them.

Although the hard work of some governors were acknowledged and appreciated by teachers many thought the problems at underperforming schools were exacerbated by the lack of capacity of the SGBs. A teacher articulated it this way:

\begin{abstract}
"They are not well educated to know the government policy in education. SGB members are not qualified to help, though they (SGBs) are trying but one must acknowledge that we don't have the strongest in terms of educational background and knowledge when it comes to the members of the SGB".
\end{abstract}

\subsection{Negative impact on teaching}

Teachers made reference to a number of implications that these shortcomings and non-performance of the SGBs had on their teaching. Two central issues were identified; firstly, teachers have to spend excessive amounts of time and resources on fund raising at their schools because governors were not doing what was expected of them; secondly, teachers (and learners) often had to endure disruption and conflict as result of violent and aggressive behaviour in the classroom caused by learners who were not adequately sanctioned or disciplined by SGBs. Teachers also mentioned the demoralising and non-appreciative working environment at their schools caused by governors not willing to act, address the cause(s) or deal with disruptive behaviour. They claimed that the unsupportive attitude and lack of appreciation and respect of SGBs for their difficult position at township schools, as well as for their efforts and labour as educators, added to their lack of motivation.

\section{Conclusion}

The set of responsibilities and menu of functions to be performed by a properly constituted SGB is wide ranging and demanding. Members of SGBs need to have a well-resourced and well-constituted SGB body to perform these functions effectively. In addition to this SGB members need to work well with the principal and SMT to play a meaningful role in the running of the school.

The evidence points to a disjuncture between the expectations of the different constituencies of schools on the one hand and the SGB on the other. This credibility gap between how positive SGBs rate themselves and how differently principals, school management members and teachers perceive them might be indicative of an unrealistic and inaccurate assessment amongst certain SGBs about their own competencies and the relative value of their contribution towards the functioning of the schools they govern.

From the above discussion, it is evident that the system in its current form is not working optimally for underperforming schools. The present model of school governance yields no real benefits to schools in dire need of assistance and empowerment in critical areas like drawing up annual budgets and fundraising. This might point to the fact that the SGB model in its current form might be fundamentally flawed within the context of underperforming schools.

\section{Recommendations}

\subsection{Recommendation 1: Strengthen leadership and management}

Improve the relationship between the Principal, SMT and SGB 
The leadership, management and governance provided at school level can be conceptualised and presented as a 'leadership triangle', representing the relationship between the three most important leadership components at the school level namely, the principal, the SMT, and the SGB.

\subsection{Recommendation 2: Revisit the current policy of a standard model of school governance at South African schools}

It is recommended that the present approach and model of school governance in South Africa be revisited.

SGBs in their current form appear to be fundamentally flawed and not working in the context of underperforming schools. Both principals and educators indicated that SGBs contributed only marginally to the functioning of these schools because parents typically lack organisational, managerial and technical capacity, which prevents them from supporting school management and the teacher corps in critical areas like drafting of the annual school budget, fundraising, and the effective implementation of disciplinary procedures. A possible route to strengthen the capacity of SGBs is through the targeted nominations of highly skilled individuals from civil society, private sector companies and academia.

\subsection{Recommendation 3: Improve the capacity of School Governing Boards}

It is recommended that the present training programmes for members of SGBs be assessed and evaluated in terms of their outcomes.

The existing package of training programmes for SGBs at underperforming schools is clearly not showing the desired outcomes. The WCED should critically interrogate both the relevance and quality of the content as well as the accessibility of it given the low level of formal education of many governors.

\subsection{Recommendation 4: Assist learners with special needs}

It is recommended that policies and services are developed specifically for underperforming schools to deal with learners with special needs. It is also recommended that a concerted effort is made to improve the infrastructure, facilities (especially toilets) and amenities at schools to accommodate learners' special needs so that they can function effectively.

The research showed that learners with special needs are not well managed at underperforming schools. This includes both improving access to specialised services, such as psychological and remedial teaching services, as well as up-skilling of the teacher corps to improve their ability to identify learners requiring such services.

\subsection{Recommendation5: Improve the monitoring and evaluation of the performance of teachers}

It is recommended that teacher performance be closely monitored and evaluated.

Evaluation of the level of academic progress that takes place in classrooms should be non-negotiable. The fact that nearly a quarter of the teachers interviewed declared that monitoring was, at best, a rare occurrence or, at worst, never happened, clearly suggests that consistent monitoring of performance of teachers at underperforming schools presents a serious challenge. It also points to bad management at these schools.

It is recommended that skipping classes, absenteeism and late-coming be strictly monitored and recorded.

There are many instances where teachers are absent, skip classes or arrive late at school. The leadership and management of the school must ensure that all these instances are strictly monitored and recorded.

\subsection{Recommendation 6: Improve school safety, particularly in the classroom itself}

A suite of interventions is necessary in dealing with this issue, ranging from behaviour modification programmes to the development of conflict resolution skills and disciplinary codes. These interventions should target both learners and teachers.

\subsection{Recommendation 7: Improve morale and attitudes of learners and teachers alike}

It is recommended that development programmes be offered for both teachers and learners at underperforming schools.

Principals and teaching staff at underperforming schools often have to confront a range of issues that are beyond the scope of teaching; issues that emanate from the social environment from which learners come. The research 
highlighted that even if quality education is provided, as in the case of Typology 1 schools, since the dysfunctional communities in which many learners live perpetuate cycles of violence, abuse, and poverty, this is likely to have minimal impact on the lives of learners if factors emanating from their socio-economic environment are not addressed.

It is for this reason that we recommend that a comprehensive personal development programme be developed and run during the learners' entire high school career. This programme needs to promote strategies that build the self image and self esteem of young people. It should also reinforce good behaviour and promote attitudinal changes and values that emphasise the excellence of personal growth and development.

\section{References}

Adams, F., \& Waghid, Y. (2005). In defence of deliberative democracy: challenging less democratic school governing body practices. South African Journal of Education, 25(1): 25-33.

Brown B \& Duku N (2008). Negotiated identities: dynamics in parents' participation in school governance in rural Eastern Cape schools and implication for school leadership. South African Journal of Education, 28:431-450.

Babbie, E., \& Mouton, J. (2001). The Practice of Social Research. Cape Town: Oxford University Press.

Bayat, A., Louw,W., and Rena, R. (2014) " The Impact of Socio-economic factors on the performance of selected high school learners in the Western Cape, South Africa", Journal of Human Ecology, 45(3):183-196.

Clase, P., Kok, J. \& Van Der Merwe, M. (2007). Tension between school governing bodies and education authorities in South Africa and proposed resolutions thereof. South African Journal of Education, 27(2): 243- 263.

Gamage, D. (2001). Models of self- governance in schools: Australia and the United

Kingdom, International Journal of Educational Management Compare, 15: 39-44.

Heystek, J. (2004). School governing bodies: the principals burden or light of his/her life? South African Journal of Education, 24(4): 308312.

Heysteck J, \& Paquette, J. (1999). Educational governance in South Africa and Canada: changing frameworks for decision making and participation. Education and Law Journal, 9: 185- 209.

Ramadiro Brian and Salim Vally (2005) School Governing Bodies: Rights and Responsibilities, Pretoria: Educational Rights Project retrieved from http://www.erp.org.za/pdf/governance\%20booklet_WEB.pdf accessed on 3 April 2014.

Raj Mestry (2006) The functions of school governing bodies in managing school finances. South African Journal of Education 26(1)2738. retrieved from file:///C:/Users/admin/Downloads/25053-31770-1-PB.pdf accessed on 3 April 2014.

Rena R (2008). Financing education and development in Eritrea - Some implications. Manpower Journal, 43(1): 73-97.

Van Deventer, I. (2003). Successfully involving the Community. (In Van Deventer, I., \& Kruger, A.G. (eds.). An Educators guide to School Management Skills.Pretoria: Van Schiak Publishers

Van Wyk, N. 2004. School governing bodies: the experiences of South African educators. South African Journal of Education, 24(1): 4954. 